\title{
Differential transfer of control of avoidance responses as a function of UCS duration'
}

J. BRUCE OVERMIER

UNIVERSITY OF MINNESOTA

Dogs received avoidance training to a visual signal in a shuttlebox followed by Pavlovian fear conditioning with two tones. One tone was paired with a $0.5-s e c$. shock, the other with a 50.0-sec. shock. Later, during avoidance extinction testing with all three stimuli, the Ss hurdled the barrier more quickly in response to the tone previously paired with the long shock. Comparisons with control Ss indicated that the differential responding was due to UCS duration.

The studies of UCS duration in Pavlovian fear conditioning with skeletal-motor responses as the index of conditioning have produced inconsistent results (Mowrer \& Solomon, 1954; Strouthes, 1965)。This experiment was designed to determine whether different UCS durations used during Pavlovian fear conditioning subsequently result different strengths of instrumental avoidance responding and greatly extend the range of durations heretofore studied.

\section{Apparatus and Method}

The Ss were 23 adult mongrel dogs. Sixteen Ss were randomly assigned to two equal groups. The remaining seven Ss were discarded because they failed to meet an avoidance learning or pretest criterion.

The apparatus consisted of a two-way shuttlebox with two compartments separated by an adjustable barrier. For training and testing, the barrier was set approximately at S's shoulder height. A masking white noise was continuously present at $75 \mathrm{~dB}$ SPL. Two tones, 400 and $1200 \mathrm{cps}$ at $85 \mathrm{~dB}$ SPL, were used as signals. A third signal was the turning off of the lamps in both compartments, resulting in a reduction of illumination from 55 to 2 lumens/sq. ft. The UCS, electric shock, was administered through a grid floor, and a commutator shifted the polarity patterns of the bars four times/sec. The shock was $550 \mathrm{VAC}$ applied through a variable current-limiting resistor in series with $\mathrm{S}$. The shock was continuously regulated at $4.5 \mathrm{ma}$. Latencies of barrier hurdling were measured automatically from signal onset until trial termination. Stimulus presentations and temporal contingencies were controlled by remotely located relay circuitry.

Treatments were administered one each day on consecutive days. The intertrial intervals during all treatments were $1 \mathrm{~min}$.

Each $\mathrm{S}$ received four $60-\mathrm{sec}$. pretest presentations of each of the three signals in a random order. If $S$ jumped the barrier during any signal presentation, it was discarded.

Each $S$ received instrumental avoidance training by the method of emergence. The $\mathrm{S}^{\mathrm{D}}$, dimmed illumination, was paired with shock in a delay conditioning procedure.
The $S^{D}$-shock onset interval was 10 sec. The S's barrier jumping response terminated the trial and the $\mathrm{S}^{\mathrm{D}}$ or the $\mathrm{S}^{\mathrm{D}}$-shock complex, whichever was present If no response occurred within $60 \mathrm{sec}$. after $\mathrm{S}^{\mathrm{D}}$ onset, the trial was automatically terminated. Training trials were presented until $\mathrm{S}$ met the avoidance learning criterion of 20 consecutive trials on which $S$ avoided shock. If the criterion was not reached within 150 trials, that $\mathrm{S}$ was discarded.

During Pavlovian fear conditioning, the S was confined to one compartment of the shuttlebox by a dropgate; therefore, $\mathrm{S}$ could perform neither the escape nor avoidance responses. Each $\mathrm{S}$ received Pavlovian fear conditioning with two tones. Figure 1 shows the two kinds of Pavlovian conditioning trials administered to the experimental and control groups. For the experimental group, one tone, $\mathrm{CS}_{1}$, was paired with a short, 0.5-sec. shock, while the contrasting tone, $\mathrm{CS}_{2}$, was paired with a long, 50.0-sec. shock. The CS-UCS onset interval was $10 \mathrm{sec}$., and the CS and UCS terminated together. ${ }^{2}$ For the control group, both tones were paired with short, 0.5-sec. shocks. The CS-UCS interval was 10 sec. One tone, $\mathrm{CS}_{1}$, terminated with the UCS; the contrasting tone, $\mathrm{CS}_{2}$, completely overlapped the UCS and terminated $49.5 \mathrm{sec}$. later. Therefore, the control group provides a control for CS duration effects, independent of UCS duration and the CS-UCS onset interval. A sequence of 16 Pavlovian fear conditioning trials, eight to each CS-UCS pair, was administered twice, once with $\mathrm{S}$ confined in each half of the shuttlebox. Assignment of the tone to be reinforced was counterbalanced.

Following conditioning, $\mathrm{S}$ was returned to the shuttlebox with the dropgate raised, and additional instrumental avoidance training with the visual $\mathrm{S}^{D}$ was administered until $S$ again met the avoidance learning criterion.

Transfer testing followed retraining. The UCS was never presented during transfer testing; therefore all test trials were extinction trials. The visual and audi-

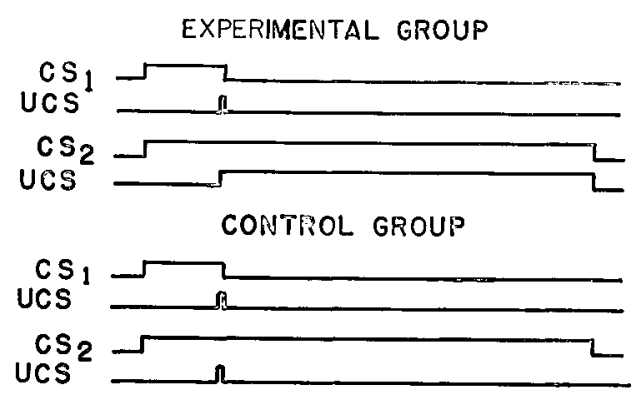

Fig. 1. A schematic representation of the CS-UCS arrangements. 
tory signals were presented in five counterbalanced blocks of 24 trials, eight to each signal, for a total of 120 test trials. During testing, a signal was terminated by S's jumping the barrier; a signal was arbitrarily terminated by $\mathrm{E}$ if no response occurred within 60 sec. after signal onset.

Results

Statistical analyses were performed on individual reciprocal median latencies of response to each signal for each block of 24 test trials. The mean values are presented in Fig. 2. The two groups did not differ in total responding (Groups $F<1, d f=1 / 14, n . s_{\text {. }}$ ) or in their responding to the visual $\mathrm{S}^{\mathrm{D}}(\mathrm{t}=0.06, \mathrm{df}=42$, $\mathrm{p}>.50)$. Both groups showed a marked extinction trend, primarily to the tone CSs (Blocks $F=20.05$, df $=4 / 56$, $\mathrm{p}<.01$, and Stimuli by Blocks $F=2.13, \mathrm{df}=8 / 112$, $\mathrm{p}<.05)$.

The experimental group responded more quickly to $\mathrm{CS}_{2}$, previously paired with the long UCS, than to $\mathrm{CS}_{1}$, previously paired with the short UCS $(t=2.10, d f=28$, $\mathrm{p}<.05)$. The control group's $\mathrm{CS}_{2}$ treatment was the control condition for CS duration effects during the experimental group's $\mathrm{CS}_{2}$ treatment. The experimental group responded significantly faster to $\mathrm{CS}_{2}$ than the control group did to $\mathrm{CS}_{2}$, a tone of the same duration but paired with the shorter $\operatorname{UCS}(t=2.48, d f=42, p<.05)$.

The $\mathrm{CS}_{1}$ conditioning treatment was identical for the two groups, and the two groups did not differ in their responding to this common stimulus $(t=0.99, \mathrm{df}=42$, $p>.30)$. However, the two groups' responses to $\mathrm{CS}_{2}$ relative to $\mathrm{CS}_{1}$ were different. The experimental group responded more quickly to $\mathrm{CS}_{2}$ than to $\mathrm{CS}_{1}$, while the control group tended to respond more slowly to $\mathrm{CS}_{2}$ than to $\mathrm{CS}_{1}(t=1.85, \mathrm{df}=28, \mathrm{p}=.07)$. This inversion is reliable (Groups by Stimuli . $F=4.10, d f=2 / 28, p<.05$ ). Discussion

The degree of transfer of control of a previously

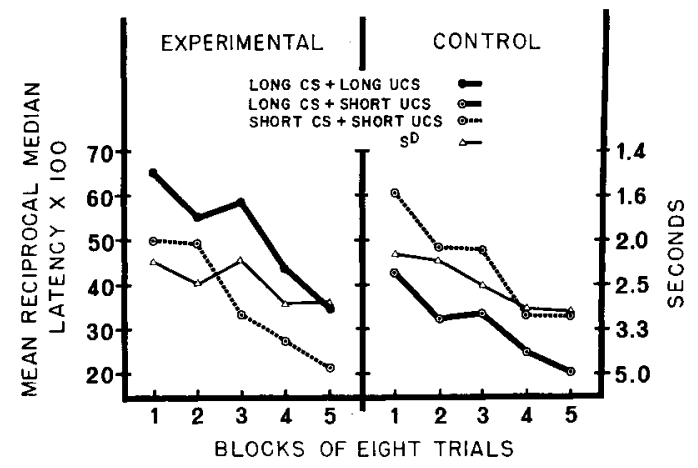

Fig. 2. Mean of individual reciprocal median response latencies to each stimulus for each block of test trials. Each point represents 64 response latencies. learned avoidance response was a positive function of the UCS duration employed during the Pavlovian fear conditioning phase. Both between-groups and withingroups comparisons revealed this. The control group indicates that the responding more rapidly to the tone paired with the long UCS than to the tone paired with the short UCS is due to the UCS duration used and not to the CS duration. Thus, the efficacy of Pavlovian fear conditioning is determined, at least in part, by UCS duration. This result is not in agreement with that obtained by Strouthes. In addition, this result is not in agreement with those experiments in which ANS responses were the index of conditioning (Bitterman, Reed, \& Krauskopf, 1952; Wegner \& Zeaman, 1958). This latter disagreement, however, might be due to factors which result in an inconsistent relationship between ANS and skeletal-motor indices of conditioning (Jaworska, Kowalska, \& Soltysik, 1962).

The counter-intuitive notions about the relative efficacy of Pavlovian fear conditioning as a function of UCS duration derived by Mowrer (1960, p. 85) and by Miller (1951, p. 375) are not confirmed by the present experiment. Longer UCS durations during Pavlovian fear conditioning can result in stronger conditioned fear, even though the CS-UCS onset interval is constant (Mowrer) and even though shock termination is delayed (Miller).

\section{References}

Bitterman, M. E., Reed, P., \& Krauskopf, J. The effect of the duration of the unconditional stimulus upon conditioning and extinction. Amer. J. Psychol., 1952, 65, 256-262.

Jaworska, K., Kowalska, M., \& Soltysik, S. Studies in the aversive classical conditioning. I. Acquisition and differentiation of motor and cardiac conditioned classical defense reflexes in dog. Acta Biol. exp. Warsaw, 1962, 22, 102-113.

Miller, N. E. Comments on multiple-process conceptions of learning. Psychol. Rev., 1951, 58, 375-381.

Mowrer, O. H. Learning theory and behavior. New York: John Wiley, 1960.

Mowrer, O. H., \& Solomon, L. N. Continuity vs. drive-reduction in conditioned fear: The proximity and abruptness of drive-reduction. Amer. J. Psychol., 1954, 67, 15-25.

Strouthes, A. Effect of CS-onset UCS-termination delay, UCS duration, CS-onset UCS-onset interval, and number of CS-UCS pairings on conditioned fear response. J. exp. Psychol., 1965, $69,287-291$.

Wegner, N., \& Zeaman, D. Strength of cardiac conditioned responses with varying unconditional stimulus durations. Psychol. Rev., 1958, 65, 238-241.

\section{Notes}

1. This research was directed by Dr. Richard L. Solomon and supported by a grant to him from U. S. Public Health Service $\left(\mathrm{MH}^{-}\right.$ 04202).

2. Thus, both CSs were paired equally close with both UCS onset and UCS termination. The possible importance of this relationship has been argued (Mowrer, O. H. Learning theory \& personality dynamics. New York: Ronald Press, 1950, p. 278-280). 